Social Work/Maatskaplike Werk Vol 50 No 3; (2)

http://socialwork.journals.ac.za/pub. http://dx.doi.org/10.15270/50-2-403

A CONTENT ANALYSIS OF THE SOUTH AFRICAN NATIONAL DRUG MASTER PLAN: LESSONS FOR ALIGNING POLICY WITH SOCIAL DEVELOPMENT If drug policies, such as the South African National Drug Master Plan 2006-2011 (NDMP2), are drafted according to a social developmental perspective, the efforts of stakeholders could be strengthened to mitigate substance abuse, eradicate drug-related crimes, and contribute towards achieving social development goals. This study determined whether the NDMP2 is drafted in accordance with a social development perspective. Quantitative research, with content analysis as research strategy, was adopted to determine whether indicators of social development are embedded in the manifest content of the NDMP2. Results show the NDMP2 has both strengths and limitations when interpreted from a social development perspective.

Stephan Geyer, Antoinette Lombard, University of Pretoria, Pretoria, south Africa

Abstract 


\section{A CONTENT ANALYSIS OF THE SOUTH AFRICAN NATIONAL DRUG MASTER PLAN: LESSONS FOR ALIGNING POLICY WITH SOCIAL DEVELOPMENT}

\section{Stephan Geyer, Antoinette Lombard}

\section{INTRODUCTION}

The World Drug Report 2013 states that substance abuse issues should be addressed from a developmental approach when developing the post-2015 development agenda (United Nations Office on Drugs and Crime [UNODC], 2013:iv). Inherent in the document is the recognition that substance abuse and drug-related crimes should be managed with a greater emphasis on a social development perspective to enable countries to achieve their social development goals. Substance abuse - including alcohol, illicit and psychotropic drugs, and drug-related crimes, ranging from drug manufacturing and trade to trafficking - is a worldwide phenomenon that impacts negatively on the achievement of development outcomes (UNODC, 2013; World Health Organisation [WHO], 2011). The first attempt by the United Nations to address substance abuse as well as drug-related crimes came about through the Single Convention on Narcotic Drugs, 1961, as amended in 1972 (United Nations [UN], 1972). This was followed by the Convention on Psychotropic Substances, 1971 (UN, 1971) and the United Nations Convention against Illicit Traffic in Narcotic Drugs and Psychotropic Substances, 1988 (UN, 1988). Unfortunately these Conventions, which are premised on the belief that all countries should be drug-free, are neither practical nor in line with the fundamentals of a social development approach towards welfare (Bewley-Taylor, 2003:171,178).

The African continent established portfolio committees and protocols to manage the negative effects of substance abuse and drug-related crimes on the achievement of development goals (Mashele, 2005:1). The African Union (AU) established the Social Affairs Portfolio (Department of Foreign Affairs, 2004), while the Southern African Development Community (SADC) drafted a Protocol on Combating Illicit Drugs (1996) and has initiated a Regional Drug Control Programme (1998) (Franzern, 1999:2; Mashele, 2005:7). This protocol and programme are explicitly applicable to member states of SADC, including South Africa.

During apartheid, prior to 1994, South Africa followed a criminal model in the management of substance abuse and drug-related crime, informed by various pieces of legislation (Geyer, 2012:18). Since the country's democratisation in 1994, the Reconstruction and Development Programme has paved the way for the social welfare sector to respond to people's basic needs and human rights, and to adapt welfare services according to a developmental approach with the aim of "promot[ing] social justice ... build[ing] human capabilities and enhanc[ing] livelihoods and social functioning" (Patel, 2005:208). With the adoption of the White Paper for Social Welfare, the social welfare sector responded to the realisation of South Africa's development outcomes through the adoption of a social development approach towards welfare. The White Paper for Social Welfare created the framework for addressing all social ills, including substance abuse, which were to be dealt 
with from a social development perspective. Within this context the first policy to deal with substance abuse and drug-related crimes within a social developmental context was the National Drug Master Plan 1999-2004 (NDMP1). The NDMP1 showed that "[the] South African Government is ... committed to reducing both the supply of illegal drugs and the demand for them through a wide range of actions and programmes" (Department of Welfare, 1999:3). However, the National Drug Master Plan was only "the beginning" (Department of Welfare, 1999:46) of the shift, and Parry (1998:62) aptly criticised it because "one of the things that is missing from the Master Plan is a clear articulation of the way in which alcohol and other drugs impact on other national priorities, e.g. development". In an attempt to address its limitations, the revised National Drug Master Plan 2006-2011 (NDMP2) made an effort to design a policy that reflects South Africa's "responses to the substance abuse problem as set out by UN Conventions and other international bodies" (Department of Social Development [DSD], 2007a:4).

This paper reports on a study conducted to analyse the content of the NDMP2 from a social development perspective. Consequently, the research questions which guided the study were: (1) "To what extent is the content of the NDMP2 in accordance with a social development perspective?", and (2) "What lessons could be learnt to draft and implement drug policies which contribute towards the realisation of countries' development goals?" It is the premise of this paper that if drug policies, such as the South African NDMP2, are drafted according to a social development perspective, they could contribute to the achievement of the country's development goals.

The article starts with a brief overview of the theoretical framework underpinning the study, namely social development. Next the discussion focuses on the content of the NDMP2, including substance abuse and drug-related crime trends. Then the research methods, results, discussion and methodological limitations of the study are presented and discussed. Finally, the paper outlines the conclusions on the alignment of the NDMP2 with a social development perspective and ends with recommendations.

\section{THEORETICAL FRAMEWORK}

Contrary to neoliberalism, a social development approach asserts that in order to enhance the welfare of all, governments, communities, social service organisations and individuals should promote both human and economic development (Midgley \& Sherraden, 2000:436-438; Midgley \& Tang, 2001:245-247). With the adoption of the ten principal commitments at the World Summit for Social Development in Copenhagen in 1995, and the Millennium Development Goals (MDGs) in 2000, social development was "undoubtedly reinvigorated ... [although] significant differences about the nature of social development practice and the conceptual ideas underlying different interventions persist" (Midgley, 2010:11). For the purpose of this paper, Lombard's (2007:299) definition of social development was adopted, namely that it is "distinguished as (1) an ultimate (end) goal of development activities; and (2) as an appropriate approach to social welfare and thus an intervention strategy that incorporates social and economic processes to achieve social development as its ultimate goal." 
Within the context of this definition, social development is regarded as a comprehensive approach to welfare which is universalistic, interventionist (i.e. governments should create an enabling environment for development processes to combat poverty), empowerment oriented (both on a personal and collective level), capacity-building oriented (i.e. attending to citizens' human, social and economic capital development), people centred (i.e. participatory, and anchored in human rights) and multi-sectoral (i.e. various disciplines and sectors work together towards social progression) (Gray, 2002, 4-8; Green \& Nieman, 2003:162-166; Lombard, 2005:211-212; Midgley \& Tang, 2001:247; Patel, 2005:30).

Similarly, Patel (2005:205-206) distinguishes five core themes that epitomise social development, namely (1) a rights-based approach; (2) development processes focusing on human, social and economic capital development; (3) democracy and participation of welfare service users; (4) a pluralist approach, acknowledging the concerted efforts of multiple sectors to achieve development; and (5) bridging the divide between micro and macro approaches. Within the South African context social development is encapsulated in a number of principles, including equity, non-discrimination, social justice, transparency and human rights (Ministry for Welfare and Population Development, 1997:16-17), which is in accordance with the Constitution of South Africa, 1996. Lombard (2005) and Patel and Hochfeld (2008) have developed social development indicators to explore the transformation of South African social welfare services within the NGO sector towards developmental practice. However, the work of these scholars did not delineate the dimensions, themes and features (i.e. indicators) of a social development perspective for drug policy in South Africa, which is the focus of this article. In the study that this article is reporting on, Geyer (2012:53-59) demarcated ten dimensions, with associated themes and features, to outline a social development perspective for drug policy in South Africa. The dimensions, based on an in-depth literature review of the theoretical concept of "social development", are as follows: capital development, innovation, integrated service-delivery strategy, intervention by social service professionals, levels of service delivery, mandate, partnerships/welfare pluralism, principles, rights-based approach and target groups (compare Burke \& Harrison, 2009; DSD, 2006, 2008; Gray, 2002; Green \& Nieman, 2003; Ife, 2001; Lombard, 2009, 2008, 2005, 2003; MacGregor, 1999; Mayadas \& Elliott, 2001; Midgley, 2010, 1995; Midgley \& Tang, 2001; Ministry of Welfare and Population Development, 1997; Noyoo, 2005; Patel, 2005; Patel \& Hochfeld, 2008; Patel \& Selipsky, 2010; Payne, Adams \& Dominelli, 2009; Reynecke, 2006; Sherraden, 2009). These dimensions, with the associated themes and features, provided a comprehensive exposition of social development which formed the theoretical framework of this study. Table 1 offers a brief overview of the dimensions and themes of a social development perspective for drug policy in South Africa. 
TABLE 1

DIMENSION AND THEMES OF A SOCIAL DEVELOPMENT

PERSPECTIVE FOR DRUG POLICY IN SOUTH AFRICA

\begin{tabular}{|l|ll|}
\hline \multicolumn{1}{|c|}{ DIMENSIONS } & \multicolumn{2}{c|}{ THEMES } \\
\hline 1. Capital development & 1.1 & Economic capital \\
\hline & 1.2 & Human capital \\
\hline 2. Innovation & 1.3 & Social capital \\
\hline & 2.1 & Research \\
\hline 3. Integrated service-delivery strategy & 2.2 & Monitoring and evaluation \\
\hline & 3.1 & Harm reduction \\
\hline 4. Intervention by social service professionals & 3.2 & Supply reduction \\
\hline & 4.1 & Bridging micro-macro divide \\
\hline 5. Levels of service delivery & 4.2 & Features of intervention \\
\hline 6. Mandate & 5.1 & Four levels of service delivery \\
\hline & 6.1 & International \\
\hline & 6.2 & African/regional \\
\hline 7. Partnerships/Welfare pluralism & 6.3 & National \\
\hline & 7.1 & Government sector \\
\hline & 7.2 & Private sector \\
\hline & 7.3 & Business sector \\
\hline 8. Principles & 7.4 & Interest groups \\
\hline 9. Rights-based approach & 8.1 & Social development principles \\
\hline & 9.1 & International measures \\
\hline & 9.2 & African/regional measures \\
\hline 10. Target groups & 9.3 & National measures \\
\hline
\end{tabular}

\section{NATIONAL DRUG MASTER PLAN 2006-2011}

This section provides a brief content overview of the NDMP2 as it is the focus of the study. At the time of writing this article the National Drug Master Plan 2013-2017 (NDMP3), as the third drug policy of South Africa, was accepted in Parliament (DSD, 2013). Prior to the finalisation of NDMP3, the research findings and recommendations of this study on the NDMP2 (Geyer, 2012) were presented to the Central Drug Authority (CDA) at their Annual Meeting in July 2012. A follow-up study on the NDMP3 could indicate the extent that the outcomes of the study have informed the development of the NDMP3 in line with a social development perspective.

The NDMP2 is a policy, specifically a Green Paper (Mabuza-Mokoko, 2011), with a vision of "a drug-free society" (DSD, 2007a:13) and a mission "to implement holistic and costeffective strategies to reduce the supply and consumption of drugs and to limit the harm associated with substance use, abuse and dependency in South Africa" (DSD, 2007a:13).

The NDMP2 singles out nine priority areas, namely crime, youth, other vulnerable groups (such as children living on the street, women, people with disabilities, older persons, persons affected by HIV and Aids), community health, research and 
information dissemination, international involvements, communication, capacity building and occupational groups at risk (DSD, 2007a:13-14). Furthermore, the NDMP2 outlines the strategic interventions for substance abuse that are aimed at "actions that reduce the demand for drugs (prevention, treatment and rehabilitation)" (DSD, 2007a:22). Mabuza-Mokoko (2011) adds that this implies an integrated strategy consisting of supply reduction, demand reduction and harm reduction in order to meet the requirements of the UNODC, to which South Africa is a signatory.

The importance of collaboration among various role players in dealing with both substance abuse and drug-related crimes is echoed in the NDMP2: "Action to combat illicit trade in and the use of substances requires broad participation by all spheres of government, organisations, the business sector and civil society" (DSD, 2007a:27). The NDMP2 outlines the roles and responsibilities of role players in government, the business sector and civil society in the fight against substance abuse and drug-related crimes.

The NDMP2 states that "Ongoing monitoring and evaluation are required to measure progress and achievements in respect of set objectives and the implementation of the NDMP[2] by all stakeholders" (DSD, 2007a:39). Monitoring and evaluation of the NDMP2 is the responsibility of the CDA. The CDA consists of various stakeholders from government departments and NGOs, who are appointed by the Minister of Social Development in accordance with the Prevention and Treatment of Drug Dependency Act 20 of 1992 . The CDA is supported by the CDA Secretariat, located in the National DSD with its "core role ... to drive the day-to-day work of the CDA ensuring that decisions taken at CDA meetings are carried out, especially with regard to the implementation of the NDMP[2]" (DSD, 2007a:28).

The need for a drug policy such as the NDMP2 is evident in the substance abuse and drug-related crime trends in South Africa.

\section{Substance abuse and drug-related crime trends}

During the implementation of the NDMP2, alcohol abuse stabilised, while drug abuse increased (DSD, 2010:5; WHO, 2011). With the South African population estimated at over 50 million, the substance abuse trends can be summarised as follows: 2.15 million citizens are considered problem alcohol users (DSD, 2010:16). Between 20.1 and 34.9 litres of pure alcohol are consumed per capita per annum (DSD, 2010:16; WHO, 2011). The most frequently consumed drink is beer, followed by African traditional beer, wine, brandy, alcohol fruit beverages, whisky, fortified wine and sparkling wine (DSD, 2010:17). It is alarming that alcohol abuse amongst children and females of childbearing age increased (DSD, 2010:5). Problem drinking affects $88 \%$ of the population (DSD, 2010:17), whilst treatment centres cannot deliver on the treatment demand (Parliamentary Monitoring Group, 2013). Multiple drug abuse, especially amphetaminetype stimulants (ATS) and cannabis, are reported in between $30-45 \%$ of treatment admissions (UNODC, 2013:11). Cannabis is the drug most used, with 3.2 million users, followed by 0.32 million people who use ATSs (including Ecstasy, methamphetamine, methcathinone, "Tik") (DSD, 2010:12). During the implementation of the NDMP2, the 
abuse of heroin and ATS increased, while cocaine remained stable (UNODC, 2013:11). With the exception of opiates, the drug abuse patterns of South Africans are higher than the global norms (DSD, 2010:12). Also alarming is the fact that new psychoactive substances, especially traditionally used substances, such as khat or ibogaine, are emerging (UNODC, 2013:xiii). Amidst the high levels of substance abuse, social ills are becoming more rampant, i.e. drug use and HIV infection, and alcohol use and tuberculosis (Parliamentary Monitoring Group, 2013). The social and economic cost of substance abuse is estimated at $6.4 \%$ of the GDP, or approximately R136 380 million per annum (DSD, 2013:20).

The NDMP2 states that South Africa's "international air links, porous borders and modern telecommunication and banking systems" enable drug trafficking (DSD, 2007a:10). Therefore, role players such as the South African Police Service (SAPS) and South African Revenue Service (SARS) are playing a critical role to reduce the supply of drugs. For the period between 2009 and 2010 twenty-five clandestine drug laboratories were identified; 567 hectares of cannabis plantations (estimated value R397 million) were destroyed; 165 drug couriers and 265 consignments of drugs (estimated value R437 million) and $48 \mathrm{~kg}$ ATSs were seized (DSD, 2010:30-35; UNODC, 2012, 2013).

\section{RESEARCH METHODS}

To answer the two research questions, the study's goal was to analyse and describe the manifest content of the NDMP2 from a social development perspective. Manifest content refers to items in a document that are "directly visible [and] objectively identifiable" (Rubin \& Babbie, 2010:244-245). A quantitative research approach was adopted to determine objectively whether indicators of social development are covered in the manifest content of the NDMP2 (Neuman, 2006:323). Therefore, the research strategy was content analysis, with the unit of analysis being one policy in the public domain, i.e. the NDMP2 (Mouton, 2001:165-167).

In order to analyse and describe the content of the NDMP2 a checklist was used, which is "a certain type of questionnaire consisting of a series of items ... that indicate whether a characteristic or attribute ... is present or not" (Delport \& Roestenburg, 2011:202). Because there was no previously developed or standardised checklist available, a specific procedure was followed to develop, pilot test and implement the checklist. The checklist was comprised of the indicators for social development. Babbie (2007:125-127) and Hong and Hodge (2009:214-215) concur that indicator development consists of at least three consecutive steps: (1) an in-depth analysis of the concept (i.e. social development) in order to identify all the dimensions associated with the concept; (2) a literature study to isolate the themes (constructs) associated with each dimension; and (3) delineation of every theme through the identification of features (attributes or characteristics) which are ultimately individually operationally defined to serve as an indicator of the concept that is to be analysed. This endeavour resulted in the identification of ten dimensions, with associated themes (see Table 1). The features of each theme were operationally defined to become an indicator of social development. This process ensured that each indicator serves as a 
significant descriptor of the concept of social development, and that it is quantifiable and actually measurable (Greenwood, 2008:55).

The credibility of the checklist was ensured through both face and content validity (Krippendorff, 2004:314-315; Neuendorf, 2002:116). To comply with the required rigour of analysing manifest content, two different software packages, WordSmith Tools 6 (WS) and Microsoft Word 2010 (MsW), were utilised during the content analysis process. The reliability of the data-collection instrument was determined through intracoder agreement, which was regarded as sufficient for a study focusing on one policy document, and the calculation of the Pearson correlation coefficient ( $r$ ) (Krippendorff, 2004:215). The reliability of the checklist was confirmed, with $r=0.98$ (Pietersen \& Maree, 2007:236).

The content analysis process of Leedy and Ormrod (2005:142) was followed to analyse and describe the NDMP2. From the raw data, descriptive statistics, specifically frequencies, percentages and means were calculated with Microsoft Excel 2010. The study received ethical clearance from the Research Ethics Committee of the Faculty of Humanities at the University of Pretoria.

\section{RESULTS}

Figure 1 provides an overview of the mean scores per dimension, based on the outcome of the content analysis process with the two different software packages.

FIGURE 1 MEANS PER DIMENSION

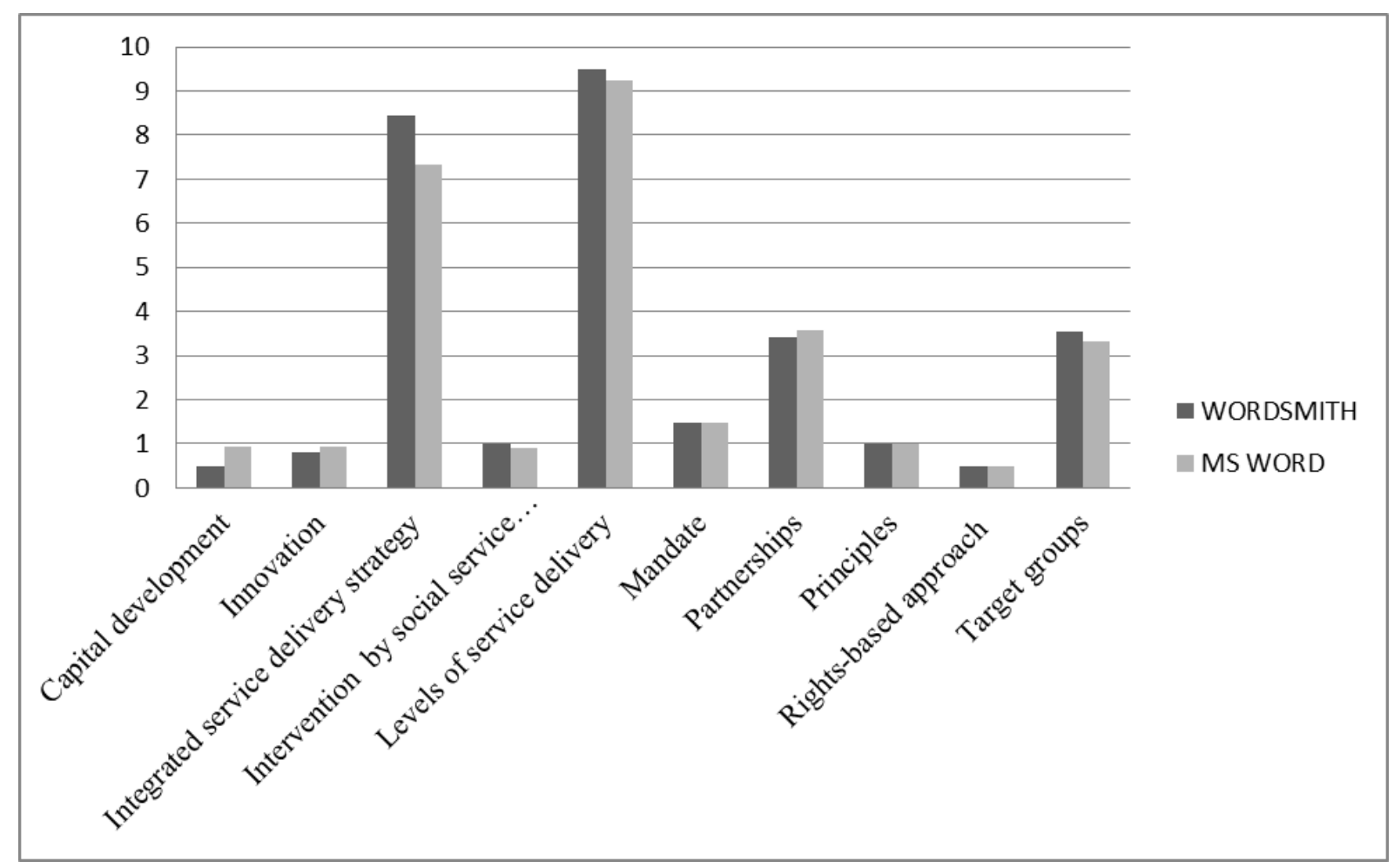


From Figure 1 it is evident that there are dimensions that are strongly emphasised in the content of NDMP2, while others are merely touched on. Those dimensions that received considerable emphasis are outlined below. First is Levels of service delivery (WS=9.5; $\mathrm{MsW}=9.25$ ), where it was determined whether the NDMP2 highlights the importance of service delivery to focus on prevention, early intervention, statutory intervention/ rehabilitation / institutionalisation, as well as aftercare and reintegration services. Closely linked to service delivery, the second most emphasised dimension is Integrated service delivery strategy (WS=8.44; $\mathrm{MsW}=7.33$ ). With this dimension the study explored whether the NDMP2 makes provision for both the harm reduction and supply reduction models in line with the prescriptions of the UNODC to which South Africa is a signatory. The third dimension is Target groups ( $\mathrm{WS}=3.56$; $\mathrm{MsW}=3.33$ ), which draws the attention of service providers to the fact that services must be provided to various vulnerable groups affected by substance abuse, such as youths, women and children. Partnerships received substantial attention in the content of the NDMP2 (WS=3.42; $\mathrm{MsW}=3.58$ ). The relatively low mean score for Mandate (WS=1.48; $\mathrm{MsW}=1.48$ ) indicates that numerous indicators for this dimension are absent from the policy content. This dimension determines whether South Africa has promulgated legislation and adopted policies to mitigate the numerous development challenges associated with substance abuse and drug-related crimes. Although referred to in the NDMP2, the dimensions Principles (WS $=1 ; \mathrm{MsW}=1$ ), Intervention by social service professionals (WS=1; MsW=0.92) and Innovation (WS=0.81; MsW=0.94) are not fully described in the policy content. From Figure 1 it is also evident that several of the dimensions are barely addressed. Dimensions such as a Rights-based approach (WS $=0.5 ; \mathrm{MsW}=0.5$ ) and Capital development (WS=0.5; MsW 0.93) (e.g. economic, human and social capital) took up the least space in the content of the NDMP2, even those these are critical dimensions from a social development perspective. Because the results obtained from the two software packages have shown a 98\% agreement correlation, the discussion that follows will be based solely on the results obtained through the content analysis with WordSmith Tools 6.

In order to evaluate the alignment of the NDMP2 with the social development perspective, the following section expands on the results and discusses the two dimensions that received the most attention in the NDMP2, namely levels of service delivery and an integrated service delivery strategy. The focus then shifts to the two dimensions with the least consideration in the policy content, i.e. rights-based approach and capital development.

\section{DISCUSSION}

\section{Dimensions receiving the most attention in the policy content}

The dimension levels of service delivery is in line with the features of a social development perspective, which indicates that all social services should be rendered on a continuum, namely prevention, early intervention, and statutory intervention / rehabilitation / institutionalisation, and aftercare and reintegration (DSD, 2007a:23-26). The levels of service delivery gives effect to one of the themes of social development, 
namely bridging the micro-macro divide. According to this theme, social services should give priority to community-based interventions, followed by services to groups and individuals (Patel \& Hochfeld, 2013:692).

Figure 2 outlines to what extent the content of the NDMP2 proposes different levels of service delivery to guide the service-delivery practices of stakeholders in targeting people affected by substance abuse and drug-related crimes.

FIGURE 2

LEVELS OF SERVICE DELIVERY

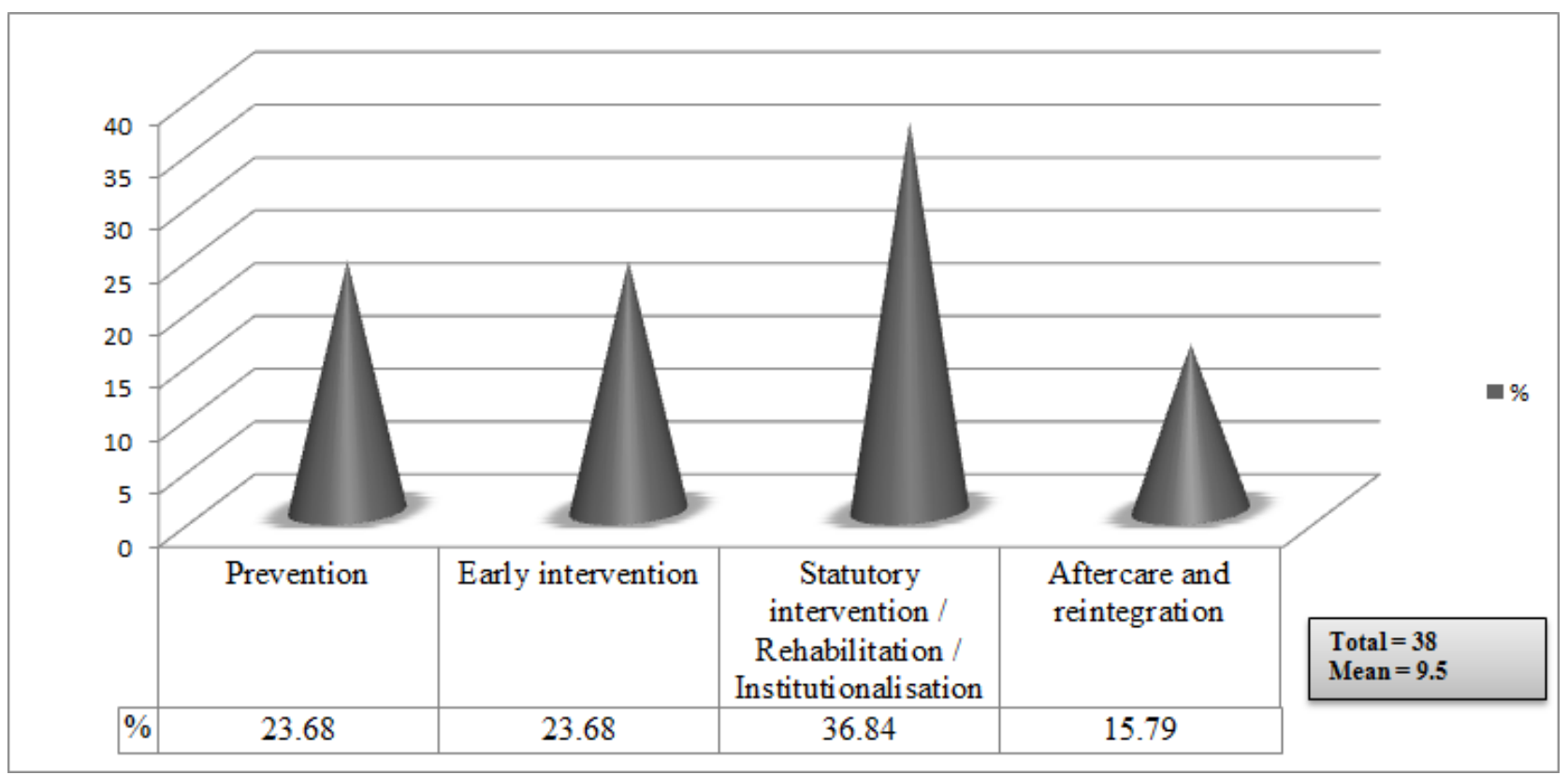

The content of the NDMP2, as reflected in Figure 2, emphasises statutory intervention / rehabilitation / institutionalisation $(f=14 ; 36.84 \%)$. Although prevention is outlined as "the most appropriate and preferred intervention" (DSD, 2007a:22), and reiterated by the UNODC (2013:iii), it is not reflected accordingly in the content of the policy. Statutory intervention / rehabilitation / institutionalisation is often associated with a residual welfare model and not with social development (Lombard \& Kleijn, 2006:215), and prevails as the dominant level of service delivery within the South African social welfare service delivery system, especially within the NGO sector (Patel \& Hochfeld, 2008:204). Myers, Louw and Fakier (2008:157-158) assert that rehabilitation remains the service-delivery option of choice in treatment centres in Cape Town, South Africa.

Prevention $(f=9 ; 23.68 \%)$ and early intervention $(f=9 ; 23.68 \%)$ share equal prominence in the content of the NDMP2. From a social development perspective this is positive, as developmental practices are supposed to prioritise prevention and early intervention services in order to enable citizens to remain productive in the economy (Hall \& Midgley, 2004:30-31). The content of the NDMP2 gives the least attention to aftercare and reintegration services $(f=6 ; 15.79 \%)$. Within a social development perspective, aftercare and reintegration services should form an essential component of the service delivery framework in order to enable people to either become or remain active in the 
economy after the completion of treatment or following incarceration. Aftercare and reintegration services are often non-existent in South Africa and therefore the need for the development of aftercare and reintegration models is high in order to prevent relapses (Van der Westhuizen, Alpaslan \& De Jager, 2011:350).

\section{Integrated service delivery strategy}

The NDMP2 is supposed to make provision for an integrated service delivery strategy, another dimension of social development, that is executed through, inter alia, two strategies: harm reduction and supply reduction (DSD, 2008:39).

Figure 3 outlines the strategies for both harm reduction and supply reduction, and how these indicators are accounted for in the content of the NDMP2.

FIGURE 3

INTEGRATED SERVICE DELIVERY STRATEGY

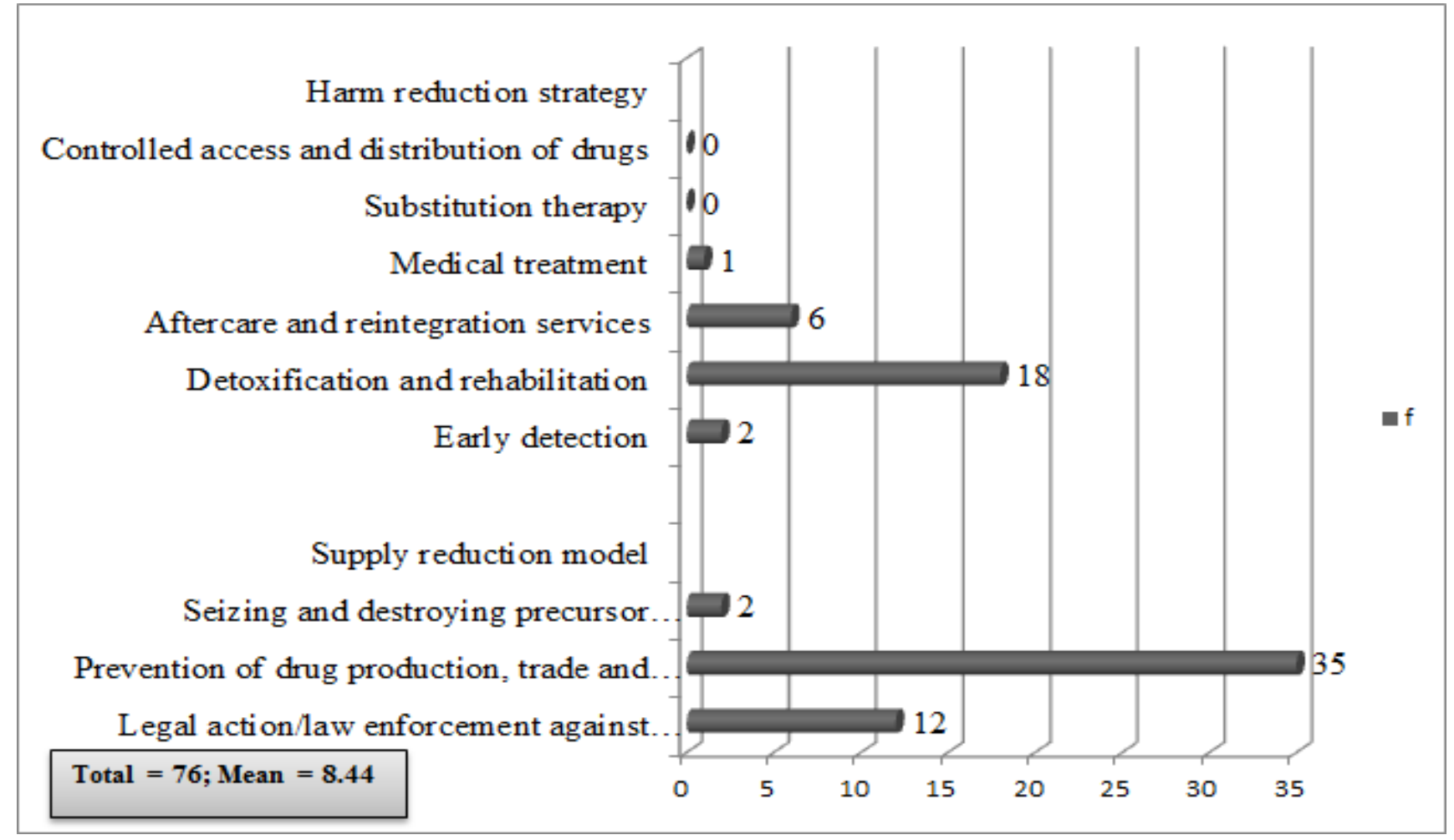

Figure 3 shows the NDMP2 gives priority to detoxification and rehabilitation $(f=18$; $23.68 \%)$, followed by aftercare and reintegration services $(f=6 ; 7.89 \%)$ and early detection $(f=2 ; 2.63 \%)$ as strategies to reduce the harm associated with substance abuse. The first annual report after the introduction of the NDMP2, namely the Central Drug Authority Annual Report 2006/07 (DSD, 2007b:35) clearly articulates that "In the South African context, several of the harm reduction interventions practised in other countries are as yet unacceptable for reasons associated with the peculiar culture and the specific religious beliefs of South Africans". Harm reduction is a sensitive issue and may explain why substitution therapy and controlled access and distribution of drugs are not outlined in the NDMP2. 
Contrary to harm reduction strategies, the findings in Figure 3 show that the content of the NDMP2 consists of numerous references to supply reduction strategies. The prevention of the production, manufacturing, trade and trafficking of drugs received the most attention $(f=35 ; 46.05 \%)$, followed by law enforcement against drug supply activities $(f=12 ; 15.79 \%)$, and the seizure and destruction of precursor materials, raw materials and products $(f=2 ; 2.63 \%)$.

The NDMP2 emphasises strategies for supply reduction at the expense of harm reduction strategies. UNODC protocol indicates that "[a]ny sensible drug policy will always combine elements of supply, demand and harm reduction" (Wodak, 2009:344). With South Africa being a signatory to the UNODC protocol (Mabuza-Mokoko, 2011), the scant attention to harm reduction strategies for people who abuse substances is a matter of concern, especially when considered from a human-rights based approach.

\section{Dimensions receiving the least attention in the policy content}

\section{Rights-based approach}

A social development approach towards welfare is embedded in a human rights ethos (Lombard \& Kleijn, 2006:227; Patel, 2005:156-158). The provision for harm reduction strategies, such as substitution therapy and controlled access and distribution of drugs, could be considered as a human right of drug users (Stevens, 2011; Wodak, 2009). Given South Africa's history of apartheid, which was characterised by gross human rights violations (Lombard, 2000:129-133), the protection of human rights is vital in a democratic society. This also applies to the field of substance abuse, especially when working with minority groups such as people with a homosexual orientation, or children living on the street (Barrett, 2010:141).

Table 2 delineates the extent to which the NDMP2 acknowledges international, regional and national measures that make provision for the protection of the human rights of people who abuse substances, or who are involved in drug-related crimes.

TABLE 2

RIGHTS-BASED APPROACH

\begin{tabular}{|lll|}
\hline & $f$ & $\%$ \\
\hline International measures & & \\
\hline Convention on the Elimination of all Forms of Racial Discrimination & 0 & 0 \\
against Women, 1979 & & \\
Convention on the Rights of the Child, 1989 & 1 & 33.33 \\
Universal Declaration of Human Rights, 1948 & 0 & 0 \\
\hline African / regional measures & & \\
\hline African Charter on Human and People Rights (1981) & 0 & 0 \\
African Charter on the Rights and Welfare of the Child (1990) & 0 & 0 \\
\hline National measures & \multicolumn{2}{l|}{} \\
\hline Bill of Rights, Constitution of the Republic of South Africa, 1996 & 2 & 66.67 \\
\hline TOTAL & 3 & 100 \\
MEAN & 0.5 & \\
\hline
\end{tabular}


From an international point of view, the content of the NDMP2, as outlined in Table 2, refers only to the Convention on the Rights of the Child, 1989 ( $\mathrm{f}=1 ; 33.33 \%$ ). The seminal Universal Declaration of Human Rights, 1948 is not reflected in the policy. The scant attention to international measures is questioned with regard to the protection of the human rights of both victims and perpetrators of substance abuse and/or drug-related crime. Furthermore, none of the regional (African) measures dealing with the protection of human rights is captured in the content of the NDMP2. However, from a national point of view, the Bill of Rights, as enshrined in the Constitution of the Republic of South Africa, 1996, ( $\mathrm{f}=2$; $66.67 \%$ ), is included in the content of the NDMP2, which is considered a key dimension of a social development approach (Lombard, 2008:160-162).

\section{Capital development}

A unique feature of a social development perspective is its emphasis on the human, social and economic capital development of welfare service users (Lombard, 2005:211; Midgley, 2010:8-10; Midgley \& Tang, 2001:247-251; Patel \& Hochfeld, 2008:198). Table 3 indicates how the content of the NDMP2 deals with capital development.

TABLE 3

CAPITAL DEVELOPMENT

\begin{tabular}{|lcc|}
\hline & $\boldsymbol{f}$ & $\boldsymbol{\%}$ \\
\hline Economic capital & & \\
\hline Black Economic Empowerment & 0 & 0 \\
Community economic development & 0 & 0 \\
Cooperatives & 0 & 0 \\
Entrepreneurship & 0 & 0 \\
Expanded Public Works Programme & 0 & 0 \\
Micro-enterprises & 0 & 0 \\
Small Business Development & 0 & 0 \\
Social grants & 0 & 0 \\
\hline Human capital & & \\
\hline Personal/ intrapersonal empowerment & 4 & 57.14 \\
Self-knowledge development & 0 & 0 \\
Skills training & 2 & 28.57 \\
\hline Social capital & & \\
\hline Community mobilisation and advocacy & 1 & 14.29 \\
Building mutual respect & 0 & 0 \\
Promoting solidarity & 0 & 0 \\
\hline TOTAL & 7 & 100 \\
MEAN & 0.5 \\
\hline
\end{tabular}

As indicated in Table 3, economic capital development is totally ignored in the content of the NDMP2. This implies that the NDMP2 includes no directives to service providers to incorporate economic development in programmes for substance-dependent persons. This poses risks to the long-term economic security of welfare service users, in particular those who are in rehabilitation for substance abuse or incarcerated for drugrelated crimes. A large-scale empirical study by Patel and Hochfeld (2008:205) on social 
work in general and statutory social work in particular confirmed that economic development receives little, if any, attention in South African social work practice.

In contrast, the NDMP2 makes provision for the human capital development of people affected by substance abuse. More specifically, personal/intrapersonal development $(f=4 ; 57.14 \%)$ and skills training $(f=2 ; 28.57 \%)$ feature in the content of the NDMP2. From the frequencies of these indicators it is concluded that service providers are informed about the necessity of investing time in the life-skills training and the building of self-esteem and self-reliance (Lombard, 2005:218) of people affected by substance abuse.

The indicators pertaining to social capital development received little attention in the NDMP2. Measures to build social capital, i.e. mutual respect and promotion of solidarity, are not addressed in the content of the NDMP2. Only one indicator, namely community mobilisation and advocacy $(f=1 ; 14.29 \%)$, is mentioned in the policy. Strong social capital in communities promotes the realisation of development goals (Thin, 2002:87), while the absence of social capital amongst community members often results in increased drug use (McKee, 2002:456).

\section{METHODOLOGICAL LIMITATIONS}

The authors acknowledge the limitations of the study, which are associated with the analysis of manifest content (Babbie, 2007:330; Hong \& Hodge, 2009:217-218; Horton \& Hawkins, 2010:383; Maschi, Baer \& Turner, 2011:248); however, the validity and the reliability of the study outweigh the methodological limitations.

It is possible that other scholars may develop other indicators for social development and reach other research findings than those in this study. Because this analysis is retrospective in nature, it could only reach conclusions about the strengths and limitations of the content of the NDMP2. Lastly, the analysis of manifest content, in line with a quantitative research approach, does not make provision for the subjective interpretation (i.e. the latent content) of policy content. It may, therefore, be possible that some indicators of social development are implied in the text, but that the objective and precise manner of manifest content analysis did not identify them.

\section{CONCLUSIONS}

Overall the research findings (see Figure 1) indicate a correlation between the content of the NDMP2 and a social development perspective. All ten dimensions associated with a social development perspective for drug policy in South Africa feature in the NDMP2, albeit with varying prominence. The content analysis of the NDMP2 presents both strengths and limitations, when interpreted from a social development perspective.

\section{Strengths of NDMP2}

The content of the NDMP2 reflects two pertinent strengths when considered from a social development perspective, namely partnerships and targeting vulnerable groups. Partnerships outline the importance and arrangements for a multi-sectoral approach that prescribes the responsibilities of stakeholders in government, the private and business 
sectors, and interest groups to manage and prevent substance abuse and to curb drugrelated crimes. Most of the vulnerable groups who are considered important from a social development perspective are prioritised in the NDMP2. Specific emphasis is put on the youth, children, women, families, older persons, people with disabilities and the poor.

\section{Limitations of NDMP2}

The limitations in the content of the NDMP2 from a social development perspective manifest in the dimensions of an integrated service delivery strategy, i.e. harm reduction strategies, a rights-based approach, capital development, levels of service delivery and target groups.

The limitation of the NDMP2 with regard to harm reduction strategies is not their absence as such, but the failure to make provision for pertinent strategies, e.g. needle exchange programmes. Harm reduction strategies are indispensable when considering the interrelation between HIV infection and drug abuse in South Africa (Parliamentary Monitoring Group, 2013).

The nexus of capital development, that is social and economic development, is not reflected in the NDMP2. On the other hand, human capital development indicators are well reflected. Policies that contribute to development goals should include indicators of human, social and economic capital development (compare Midgley \& Sherraden, 2000:438).

Although the NDMP2 describes levels of service delivery, insufficient attention is paid to prevention services, which most likely will exacerbate the substance-abuse problem in South Africa. Similarly, inadequate attention to aftercare and reintegration thwarts welfare service users from accessing opportunities for empowerment and being partners in their own development.

From a social development perspective, the NDMP2 reflects limitations in the dimension of a human rights approach, which should be a key driver of the policy. The NDMP2 should reiterate the responsibility of service providers to attend to the human rights of welfare service consumers and people incarcerated for drug-related crimes.

Although the NDMP2 attends to vulnerable groups, which has been indicated as a strength, the policy directives are not specific with regards to gay, lesbian, bisexual, and trans- and intergender people, who should be acknowledged as being vulnerable to substance abuse (Cheng, 2009:324-327; Van Wormer \& Davis, 2008:472-480).

In conclusion, the strengths and the limitations which emerged from the content analysis of the NDMP2 provide lessons for drafting and implementing drug policy in accordance with a social development perspective. Furthermore, specific lessons can also be learnt in general to align policy content with a social development perspective. 


\section{RECOMMENDATIONS: LESSONS FOR ALIGNING POLICY WITH SOCIAL DEVELOPMENT}

Strategies pertaining to demand, supply and harm reduction should receive equal attention in drug policies. As the UNODC (2013:iii) puts it: "experience has shown, neither supply reduction nor demand reduction on their own are able to solve the [substance-abuse] problem". Therefore, drug policies need to make provision for strategies such as controlled access to and distribution of drugs, and substitution therapy.

Policies, such as the NDMP2, should include from the onset the social development mandate that provides the conceptual framework that they feature in. On the international level, policy should refer to the Copenhagen commitments and MDGs. For drug policies on the African continent, regional protocols, such as the Protocol on Combating Illicit Drugs (1996) and the Regional Drug Control Programme (1998), should be contextualised. Country-specific policies, for example South African policies that mandate a social development perspective, such as the Integrated Service Delivery Model (2006), should indicate the link with policy on substance abuse and drug-related crimes.

Prevention and early intervention must be prioritised as "first line" levels of service delivery, which are complemented by treatment / rehabilitation and aftercare and reintegration services. Drug policies, and policy in general, must be specific with regard to prevention and early intervention services. In fact, the UNODC (2013:iii) lobbies for more preventative services across the globe in the fight against substance abuse and drug-related crimes.

The institutional framework of a drug policy, such as the NDMP2, should make provision for a comprehensive list of government departments and institutions, the private and business sectors, and interest groups that could play a significant role in the fight against substance abuse and drug-related crimes. This will unequivocally promote a multi-sectoral approach in substance-abuse service delivery. Policy in general should make provision for a multi-sectoral approach.

In line with the human rights ethos of social development, social service policies in particular should include gay, lesbian, bisexual, and trans- and intergender people as vulnerable groups. The effectiveness of policies is embedded in so far as it provides evidence of how interventions and service delivery should be directed towards the holistic development of people, irrespective of the social ills being addressed. Finally, social development indicators provide a broad framework to determine how policy content is aligned with a social development perspective in order to direct implementation and service delivery in achieving national and global development goals. 


\section{REFERENCES}

BABBIE, E. 2007. The practice of social research $\left(11^{\text {th }}\right.$ ed). Belmont, CA: Thomson/Wadsworth.

BARRETT, D. 2010. Security, development and human rights: Normative, legal and policy challenges for the international drug control system. International Journal of Drug Policy, 21:140-144.

BEWLEY-TAYLOR, D.R. 2003. Challenging the UN drug control conventions: problems and possibilities. International Journal of Drug Policy, 14:171-179.

BURKE, B. \& HARRISON, P. 2009. Anti-oppressive approaches. In: ADAMS, R., DOMINELLI, L. \& PAYNE, M. (eds) Critical practice in social work $\left(2^{\text {nd }}\right.$ ed $)$. New York, NY: Palgrave MacMillan.

CHENG, Z. 2009. Issues and standards in counseling lesbians and gay men with substance abuse concerns. Journal of Mental Health Counseling, 25(4):323-336.

DELPORT, C.S.L. \& ROESTENBURG, W.J.H. 2011. Quantitative data-collection methods: Questionnaires, checklists, structured observation and structured interview schedules. In: DE VOS, A.S. (ed), STRYDOM, H., FOUCHÉ, C.B. \& DELPORT, C.S.L. Research at grass roots - for the social sciences and human service professions $\left(4^{\text {th }}\right.$ ed). Pretoria: Van Schaik Publishers.

DEPARTMENT OF FOREIGN AFFAIRS. 2004. African Union in a nutshell. [Online] Available: http://www.dfa.gov.za/au.nepad/au_nutshell.htm [Accessed: 28/01/2008].

DEPARTMENT OF SOCIAL DEVELOPMENT. 2006. Integrated Service Delivery Model towards improved social services. RP31. Pretoria: Government Printers.

DEPARTMENT OF SOCIAL DEVELOPMENT. 2007a. National Drug Master Plan 2006-2011. RP05/2007. Pretoria: Government Printers.

DEPARTMENT OF SOCIAL DEVElOPMENT. 2007b. Central Drug Authority annual report 2006/07. Pretoria: DSD.

DEPARTMENT OF SOCIAL DEVElOPMENT. 2008. Central Drug Authority annual report for the year ended 31 March 2008. Pretoria: DSD.

DEPARTMENT OF SOCIAL DEVELOPMENT. 2010. Central Drug Authority Annual Report 2009/10. Pretoria: DSD. 
DEPARTMENT OF SOCIAL DEVELOPMENT. 2013. National Drug Master Plan 2013-2017. Pretoria: Government Printers.

DEPARTMENT OF WELFARE. 1999. National Drug Master Plan 1999-2004. Cape Town: CTP Book Printers.

FRANZERN, B. 1999. Illicit drugs in Southern Africa: the facts. SADC Today, 3(3):12.

GEYER, L.S. 2012. A content analysis of the National Drug Master Plan 2006-2011 from a social development perspective. Pretoria: University of Pretoria. (MSW Minidissertation)

GRAY, M. 2002. Developmental social work: a 'strengths' praxis for social development. Social Development Issues, 24(1):4-14.

GREEN, S. \& NIEMAN, A. 2003. Social development: good practice guidelines. Social Work/Maatskaplike Werk, 39(2):161-181.

GREENWOOD, T. 2008. Bridging the divide between community indicators and government performance measurement. National Civic Review, 97(1):55-59.

HALL, A. \& MIDGLEY, J. 2004. Social policy for development. London: Sage Publications.

HONG, P.Y.P. \& HODGE, D. 2009. Understanding social justice in social work: a content analysis of course syllabi. Families in Society: The Journal of Contemporary Social Service, 90(2):212-219.

HORTON, E.G. \& HAWKINS, M. 2010. A content analysis of intervention research in social work doctoral dissertations. Journal of Evidence-Based Social Work, 7:377-386.

IFE, J. 2001. Human rights and social work: towards rights-based practice. London: Cambridge University Press.

KRIPPENDORFF, K. 2004. Content analysis: an introduction to its methodology. $\left(2^{\text {nd }}\right.$ ed). Thousand Oaks, CA: Sage Publications.

LEEDY, P.D. \& ORMROD, J.E. 2005. Practical research: planning and design $\left(8^{\text {th }}\right.$ ed). Upper Saddle River, NJ: Pearson Education.

LOMBARD, A. 2000. Enhancing a human rights culture through social work practice and training. Social Work/Maatskaplike Werk, 36(2):124-140. 
LOMBARD, A. 2003. Entrepreneurship in Africa: social work challenges for human, social and economic development. Social Work/Maatskaplike Werk, 39(3):224-239.

LOMBARD, A. 2005. Impact of social services on human, social and economic development and the promotion of human rights in South Africa. Social Work/Maatskaplike Werk, 41(3):209-228.

LOMBARD, A. 2007. The impact of social welfare services on social development in South Africa: an NGO perspective. Social Work/Maatskaplike Werk, 43(4):295-316.

LOMBARD, A. 2008. The implementation of the White Paper for Social Welfare: a tenyear review. Social Work Practitioner-Researcher, 20(2):154-173.

LOMBARD, A. 2009. South Africa and Post-industrialism: developmental social welfare - a policy framework for social services with children. In: POWELL, J.L. \& HENDRICKS, J. (eds). The Welfare State in Post-Industrial Society: a global perspective. London: Springer.

LOMBARD, A. \& KLEIJN, W.C. 2006. Statutory social services: an integrated part of developmental social welfare service delivery. Social Work/Maatskaplike Werk, 42(3/4):213-233.

MABUZA-MOKOKO, E.A. 2011. Interview with the Social Work Manager, Central Drug Authority, National Department of Social Development. [Recorded]. 3 February. Pretoria.

MacGREGOR, S. 1999. Drug treatment systems and policy frameworks: a comparative social policy perspective. European Addiction Research, 5:118-125.

MASCHI, T., BAER, J. \& TURNER, S.G. 2011. The psychological goods on clinical social work: A content analysis of the clinical social work and social justice literature. Journal of Social Work Practice, 25(2):233-253.

MASHELE, P. 2005. Mainstreaming drug control into socio-economic development in Africa. Pretoria: Institute for Security Studies.

MAYADAS, N.S. \& ELLIOTT, D. 2001. Psychosocial approaches, social work and social development. Social Development Issues, 23(1):5-13.

McKEE, M. 2002. Substance use and social and economic transition: the need for evidence. International Journal of Drug Policy, 13:453-459.

MIDGLEY, J. 1995. Social development: the development perspective in social welfare. London: Sage Publications. 
MIDGLEY, J. 2010. The theory and practice of developmental social work. In: MIDGLEY, J. \& CONLEY, A. (eds) Social work and social development: Theories and skills for developmental social work. New York, NY: Oxford University Press.

MIDGLEY, J. \& SHERRADEN, M. 2000. The social development perspective in social policy. In: MIDGLEY, J., TRACY, M.B. \& LIVERMORE, M. (eds). The handbook of social policy. London: Sage Publications.

MIDGLEY, J. \& TANG, K.I. 2001. Social policy, economic growth and developmental welfare. International Journal of Social Welfare, 10(4):244-252.

MINISTRY FOR WELFARE AND POPULATION DEVELOPMENT. 1997. White Paper for Social Welfare. Notice 1108 of 1997. Government Gazette, 386(18166). Pretoria: Government Printers.

MOUTON, J. 2001. How to succeed in your master's \& doctoral studies: a South African guide and resource book. Pretoria: Van Schaik Publishers.

MYERS, B., LOUW, J. \& FAKIER, N. 2008. Alcohol and drug abuse: removing structural barriers to treatment for historically disadvantaged communities in Cape Town. International Journal of Social Welfare, 17:156-165.

NEUENDORF, K.A. 2002. The content analysis guidebook. Thousand Oaks, CA: Sage Publications.

NEUMAN, W.L. 2006. Social research methods: qualitative and quantitative approaches $\left(6^{\text {th }}\right.$ ed). Boston, MA: Allyn and Bacon.

NOYOO, N. 2005. Monitoring and evaluation for social development: A case for social work in South Africa. Social Work/Maatskaplike Werk, 41(3):229-236.

PARLIAMENTARY MONITORING GROUP. 2013. Central Drug Authority 2011/2012 Annual Report: adoption of Committee report. [Online] Available: http://www.pmg.org.za [Accessed: 24/08/2013].

PARRY, C.D.H. 1998. Comments on the National Drug Master Plan. Urban Health and Development Bulletin, 1(4):61-63.

PATEL, L. 2005. Social welfare and social development in South Africa. Cape Town: Oxford University Press Southern Africa.

PATEL, L. \& HOCHFELD, T. 2013. Developmental social work in South Africa: Translating policy into practice. International Social Work, 56(6):690-704. 
PATEL, L. \& HOCHFELD, T. 2008. Indicators, barriers and strategies to accelerate the pace of change to developmental welfare in South Africa. Social Work PractitionerResearcher, 20(2):192-211.

PATEL, L. \& SELIPSKY, L. 2010. Social Welfare Policy and Legislation in South Africa. In: NICHOLAS, L., RAUTENBACH, J. \& MAISTRY, M. (eds). Introduction to social work. Claremont: Juta \& Co. Ltd.

PAYNE, M., ADAMS, R. \& DOMINELLI, L. 2009. On being critical in social work. In: ADAMS, R., DOMINELLI, L. \& PAYNE, M. (eds). Critical practice in social work $\left(2^{\text {nd }}\right.$ ed $)$. New York, NY: Palgrave MacMillan.

PIETERSEN, J. \& MAREE, K. 2007. Statistical analysis I: Descriptive statistics. In: MAREE, K. (ed). First steps in research. Pretoria: Van Schaik Publishers.

REYNECKE, R.P. 2006. A human potential development perspective for community work. Social Work/Maatskaplike Werk, 42(1):26-36.

RUBIN, A. \& BABBIE, E. 2010. Essential research methods for social work $\left(2^{\text {nd }} \mathrm{ed}\right)$. Belmont, CA: Brooks/Cole.

SHERRADEN, M. 2009. Social work, global poverty, and development. St. Louis: Centre for Social Development, Washington University at St Louis.

STEVENS, A. 2011. Drug policy, harm and human rights: a rationalist approach. International Journal of Drug Policy, 22:233-238.

THIN, N. 2002. Social progress and sustainable development. Bloomfield, CT: Kumarian Press.

UNITED NATIONS. 1971. Convention on Psychotropic Substances, 1971. Geneva: United Nations.

UNITED NATIONS. 1972. Single Convention on Narcotic Drugs, 1961. Geneva: United Nations.

UNITED NATIONS. 1988. United Nations Convention against Illicit Traffic in Narcotic Drugs and Psychotropic Substances, 1988. Geneva: United Nations.

UNITED NATIONS OFFICE ON DRUGS AND CRIME. 2012. World Drug Report 2012. Vienna: United Nations Publication. 
UNITED NATIONS OFFICE ON DRUGS AND CRIME. 2013. World Drug Report 2013. Vienna: United Nations Publication.

VAN DER WESTHUIZEN, M., ALPASLAN, A. \& DE JAGER, M. 2011. Preventing relapses amongst chemically addicted adolescents: exploring the state of current services. Social Work/Maatskaplike Werk, 47(3):350-370.

VAN WORMER, K. \& DAVIS, D.R. 2008. Addiction treatment: a strengths perspective $\left(2^{\text {nd }}\right.$ ed). Belmont, CA: Thomson Brooks/Cole.

WODAK, A. 2009. Harm reduction is now the mainstream global drug policy. Addiction, 104:343-344.

WORLD HEALTH ORGANIZATION. 2011. Global status report on alcohol and health 2011. Geneva: WHO Press.

Dr Stephan Geyer; Prof Antoinette Lombard, Department of Social Work \& Criminology, University of Pretoria, Pretoria, South Africa. 